\title{
Graphite-teflon-tyrosinase composite electrodes for the monitoring of phenolic compounds in predominantly non-aqueous media
}

\author{
B. Serra, E. Mateo, M. Pedrero, A.J. Reviejo, and J.M. Pingarrón \\ Departamento de Química Analítica. Facultad de Ciencias Químicas. Universidad Complutense de Madrid. E - 28040 Madrid, Spain
}

\begin{abstract}
The behavior of a graphite-Teflon-tyrosinase amperometric biosensor in predominantly nonaqueous media constituted by different reversed micellar systems is discussed. Monitoring of several phenolic compounds substituted in different positions with different functional groups was carried out. The effect of the composition of the reversed micelle on the response of the tyrosinase biosensor has been analyzed. These composite bioelectrodes allow the regeneration of the electrode surface by polishing and exhibit long-term operation and stability.
\end{abstract}

\section{Introduction}

Fabrication of amperometric electrodes by incorporation of enzymes into the bulk of rigid composite electrode matrices constructed with graphite and Teflon has demonstrated to possess several practical advantages with respect to other designs $[1,2]$. Three-dimensional biocomponent reservoirs are obtained, whose surface can be easily regenerated by polishing. Moreover, enzymes are entrapped into the composite electrode matrix by purely physical inclusion with no need for covalent attachments, which leads to an easier, faster and cheaper electrode fabrication procedure, as well as to avoiding possible losses in sensitivity due to the covalent linkages. Furthermore, the absence of membranes on the electrode surface falicitates a fast response of the composite bioelectrode, and the possibility of bulk incorporation of other components such as mediators, cofactors or other biomolecules allows the fabrication of versatile biosensors.

One of the most interesting advantages of the incorporation of enzymes into graphite-Teflon composite matrices is the compatibility with organic or predominantly organic solvents. Recently, we proved the suitability of a graphiteTeflon ferrocyanide-mediated peroxidase electrode for working in a predominantly non-aqueous medium such as reversed micelles [3]. These reversed micelles, also called water-in-oil-emulsions, are composed of an organic solvent as the continuous phase, a small amount of an aqueous solution of an appropriate supporting electrolyte as the dispersed phase, and a surfactant as the emulsifying agent. These organized media have been shown to be suitable working media for the development of amperometric enzyme biosensors [46], and can be considered as universal solubilization media for both hydrophilic and hydrophobic analytes, thus allowing the enzymatic determination of substances scarcely soluble in water. Moreover, the content of water needed for the hydration of the enzyme, and, consequently, for the enzyme operation is very easy to control and optimize.

In this paper, the behaviour of a graphite-Teflon-tyrosinase amperometric biosensor in predominantly non-aqueous media constituted by different reversed micellar systems is reported. Monitoring of several phenolic compounds, with different functional groups substituted in different positions, was carried out, and therefore, the enzymatic reaction involved the catalytic oxidation of these compounds to the corresponding quinones. The electrochemical reduction of these quinones at the electrode was employed to monitor this reaction. Nowadays, the environmental significance of phenolic compounds is very well known, a lot of effort having been made on their detection and determination [7, 8]. In particular, biosensors have been widely used for this purpose. Regarding tyrosinase biosensors, some recent approaches can be cited. A graphite-epoxy-tyrosinase composite electrode with gold or palladium incorporated was applied for phenol and catechol detection in flow-injection systems [9]. Tyrosinase has also been immobilized in a thin layer of silica sol-gel on a carbon paste electrode, which retained a $50 \%$ of its activity for some phenolic compounds after fifteen days of storage in phosphate buffer at $4{ }^{\circ} \mathrm{C}$ [10]. Moreover, a tyrosinase-based amperometric biosensor detection system, in which the enzyme was coimmobilized with a conducting poly(1-vinylimidazole)based osmium polymer, was applied to the high-performance liquid chromatographic determination of phenols [11].

Very few papers deal with tyrosinase biosensors able to work in organic phase. An enzyme immobilization method using a poly(hydroxyl cellulose) hydrogel allowed the essential water required by the enzyme for the catalytic activity to be kept, and, consequently, the use of the sensor in pure organic phase [12]. Kinetic and analytical applications of organic phase tyrosinase electrodes have been discussed by entrapping the enzyme in a reticulated vitreous carbon matrix with poly(estersulphonic acid) or covalently immobilized with glutaraldehyde or polyethylene glycol in osmium polymers [13]. 


\section{Experimental}

\section{Apparatus, electrodes, and electrochemical cell}

Amperometric measurements were performed on a Metrohm 641 VA potentiostat connected to a Linseis L6512 $\mathrm{x}-\mathrm{t}$ recorder. The electrochemical cell was a BAS VC-2 cell with a BAS RE-1 $\mathrm{Ag} / \mathrm{AgCl} / \mathrm{KCl}\left(3 \mathrm{~mol} \mathrm{~L}^{-1}\right)$ reference electrode, and a Pt wire auxiliary electrode. A P-Selecta Ultrasons ultrasonic bath, and a P-Selecta thermostatic bath were also used.

\section{Preparation of graphite-Teflon-tyrosinase composite electrodes}

Rigid composite tyrosinase electrodes were prepared in the form of cylindrical pellets as follows. Graphite (ultra F purity), $0.15 \mathrm{~g}$, and tyrosinase (from mushroom, EC 1.14.18.1, activity 3000 units per $\mathrm{mg}$ of solid, Sigma), $0.030 \mathrm{~g}$, were accurately weighed, and thoroughly mixed by mechanical stirring for $3 \mathrm{~h}$ in a $0.40 \mathrm{~mL}$ suspension of a $0.05 \mathrm{~mol} \mathrm{~L}^{-1}$ phosphate buffer solution of $\mathrm{pH} 7.4$ at $4{ }^{\circ} \mathrm{C}$. Then, water was evaporated by passing an argon stream through the mixture, and the appropriate amount of Teflon powder (Aldrich) to obtain the desired final Teflon content (0.42 $\mathrm{g}$ for a $70 \%$ Teflon electrode) was added and mixed thoroughly by hand. The mixture was pressed into pellets by using a Carver pellet press at $10,000 \mathrm{~kg} \mathrm{~cm}^{-2}$ for $10 \mathrm{~min}$. These pellets were $1.3 \mathrm{~cm}$ diameter and around $0.4 \mathrm{~cm}$ thick. Several $3.0 \mathrm{~mm}$ diameter cylindrical portions of each pellet were bored, and each portion was press-fitted into a Teflon holder. Electrical contact was attained through a stainlesssteel flat-tipped screw.

\section{Reagents and solutions}

Other reagents used were, phenol (Sigma), catechol (Sigma), 2,3-dimethylphenol (Aldrich), 3,4-dimethylphenol (Aldrich), 3,5-dimethylphenol (Aldrich), 2,4-dimethylphenol (Aldrich), 4-chloro-3-methylphenol (Aldrich), 4-chloro-2-methylphenol (Aldrich), pentachlorophenol (Aldrich), ethyl acetate (Aldrich), chloroform (Aldrich), n-hexane (Panreac), dichloromethane (Panreac), dioctyl sulfosuccinate (AOT, Aldrich), Hyamine 3500 (Serva), Triton X-405 (Serva), and tetrabutylammonium perchlorate (TBAP, Aldrich). All chemicals were of analytical-reagent grade, and the water used was obtained from a Milli-Q purification system.

The stock solutions of the phenolic compounds $\left(0.16 \mathrm{~mol} \mathrm{~L}^{-1}\right)$ were water-in-oil microemulsions prepared by dissolving the appropriate amount in the reversed micelles solution formed with the organic solvent (ethyl acetate, chloroform, dichloromethane or n-hexane), the selected concentration of emulsifying agent (AOT), and the selected percentage of a $0.05 \mathrm{~mol} \mathrm{~L}^{-1}$ phosphate buffer solution ( $\mathrm{pH} 7.4$ ) as aqueous phase. More dilute standards were prepared by suitable dilution with the same components of the emulsions.

\section{Procedures}

Activation of the composite enzyme electrode was accomplished daily by immersion in a stirred $1.610^{-3} \mathrm{~mol} \mathrm{~L}^{-1}$ phenol reversed micelle (prepared with ethyl acetate, $0.1 \mathrm{~mol} \mathrm{~L}^{-1}$ AOT, and a $4 \%$ of $0.05 \mathrm{~mol} \mathrm{~L}^{-1}$ phosphate buffer), and holding the electrode at $-0.15 \mathrm{~V}$ for $10 \mathrm{~min}$. Then, the activated electrode was immersed in the electrochemical cell containing $10.0 \mathrm{~mL}$ of the corresponding reversed micelle solution, and amperometric measurements under constant stirring conditions were performed at $25.0 \pm 0.5^{\circ} \mathrm{C}$ by applying the desired potential and allowing the steady-state current to be reached. When the response obtained with the biosensor was significantly lower than the initial one (after having been used for a period of time), the electrode surface was regenerated by polishing for approximately $5 \mathrm{~s}$ on a 150 grit $\mathrm{SiC}$ paper. After use, the composite bioelectrode was stored at $4{ }^{\circ} \mathrm{C}$ in a refrigerator.

\section{Results and discussion}

The possibility of using a tyrosinase amperometric biosensor in reversed micelles was previously demonstrated by our group [4]. In that work, the immobilization of the enzyme was carried out by direct adsorption on the surface of a graphite disk electrode, the stability of the enzyme electrode being acceptable only over 48 hours. Consequently, the design of more robust tyrosinase biosensors able to work in these predominantly non-aqueous media should improve the performance of those bioelectrodes. The purely physical entrapment of tyrosinase into the bulk of the graphite and Teflon composite matrices can lead to achieve the advantageous practical properties already mentioned in the introduction section.

The performance of the biocomposite electrode in the reversed micelles was firstly tested by using the Teflon-tographite ratio in the electrode matrix, and the composition of the reversed micellar system optimized in previous works $[1,4]$. Thus, pellets containing $70 \%(w / w)$ Teflon, and reversed micelles formed with ethyl acetate as the continuous phase, $0.1 \mathrm{~mol} \mathrm{~L}^{-1}$ AOT as the emulsifying agent, and $4 \%$ phosphate buffer ( $\mathrm{pH} 7.4$ ) as the dispersed phase were employed. On the other hand, the phenolic compounds used as substrates were selected taking into account the position occupied by the different substituents. So, besides phenol, we chose phenolic compounds with the two ortho-positions free (4-chloro-3-methylphenol), with one of these positions substituted (2,4-dimethylphenol), and with the two orthopositions occupied (pentachlorophenol), because these positions are where the 1,2-quinones are formed in the enzymatic reactions [14], and whose reduction is electrochemically monitored.

Optimization of the tyrosinase loading was carried out by amperometry in stirred solutions using phenol as the substrate, and constructing three different composite biosensors with enzyme percentages of $0.4 \%, 2.0 \%$, and $5.0 \%$. 
Current-time recordings obtained for a phenol concentration of $0.4 \mathrm{mM}$, and by applying a constant potential of $-0.15 \mathrm{~V}$, at which it is known that the reduction of the quinone product can be monitored [4], showed that the steady-state current increased considerably with the tyrosinase loading in the electrode matrix. Furthermore, the steady-state current was reached more rapidly as the enzyme content increased, indicating that, as expected, more enzyme active sites were present on the electrode surface and, hence, the 1,2-quinone concentration in the diffusion layer was higher. Consequently, a $5 \%$ tyrosinase was selected for further work which, moreover, coincides with the enzyme loading reported in the literature for the construction of tyrosinase modified carbon paste electrodes [15].

\section{Effect of the composition of the reversed micelle on the response of the tyrosinase biosensor}

\section{Nature of the organic solvent}

The nature of the organic solvent employed to form the reversed micelles can affect drastically the activity and stability of the enzyme used. In general, it has been claimed that the enzyme activity is correlated with the polarity of the solvent, which can be expressed by the value of $\log \mathrm{P}$ [16]. As $\log \mathrm{P}$ increases, the hydrophobicity of the organic solvent also increases. Figure 1 shows current-time recordings obtained for $0.4 \mathrm{mM}$ phenol in different reversed micellar systems formed with $\mathrm{n}$-hexane $(\log \mathrm{P}=3.48)$, chloroform $(\log \mathrm{P}=2.24)$, dichloromethane $(\log \mathrm{P}=1.25)$, and ethyl acetate $(\log \mathrm{P}=0.66)$, as well as with some of their mixtures, $0.1 \mathrm{~mol} \mathrm{~L} \mathrm{~L}^{-1}$ AOT as the surfactant, and a $5 \%$ of a $0.05 \mathrm{~mol} \mathrm{~L}^{-1}$ phosphate buffer solution of $\mathrm{pH} 7.4$ as dispersed phase. As can be observed, the composite tyrosinase electrode exhibits a well-defined response in the emulsions formed with ethyl acetate and chloroform, which becomes a little worse when the organic solvent is dichloromethane, and practically disappears when n-hexane or a 9:1 mixture of n-hexane and ethyl acetate is employed. However, a useful signal was obtained when the emulsion was formed with a 1:1 n-hexane:ethyl acetate mixture. Although in this case, the amperometric response was approximately 5-fold lower than that registered in emulsions formed only with ethyl acetate, this mixture could be used with analytical purposes when the analyte to be determined should be extracted in nhexane.

Although it has been suggested for enzyme reactions in organic media that solvents with a $\log \mathrm{P}<2$ are not suitable for biocatalysis because they can distort the biocatalystwater interaction (i.e. stripping of the essential water layer) [16], the results shown in figure 1 allow us to conclude that the most suitable solvent for a good amperometric biosensor performance is ethyl acetate, which has the lowest log $\mathrm{P}$ value. The high dielectric constant of this solvent compared to the others ensures the conductivity of the water-inoil emulsions formed, and, as it will be demonstrated later on, it does not damage the enzyme-water interaction.

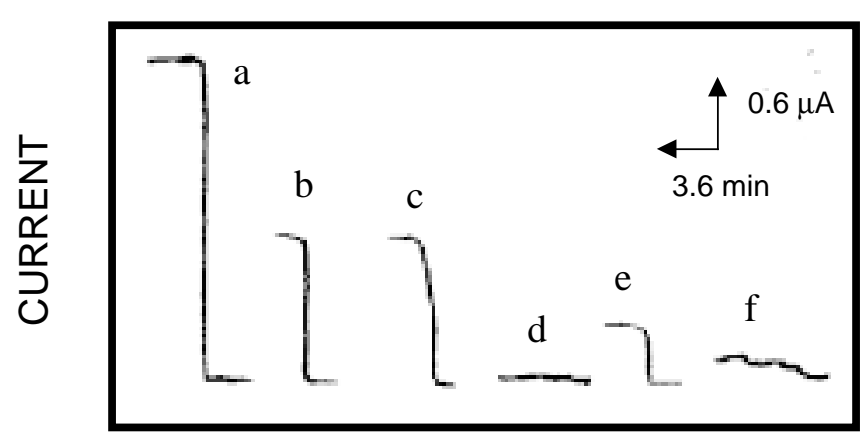

TIME

Figure 1. Current-time recordings obtained at a graphite$70 \%$ Teflon-tyrosinase electrode for $0.4 \mathrm{mM}$ phenol in $10.0 \mathrm{~mL}$ of reversed micelles formed with: (a) ethyl acetate, (b) chloroform, (c) dichloromethane, (d) n-hexane, (e) n-hexane:ethyl acetate $1: 1$, (f) n-hexane:ethyl acetate 9:1, as continuous phase, a $5 \%$ of $0.05 \mathrm{~mol} \mathrm{~L}^{-1}$ phosphate buffer solution (pH 7.4) as dispersed phase, and $0.1 \mathrm{~mol} \mathrm{~L}^{-1} \mathrm{AOT}$ as the emulsifying agent; $E_{a p p}=$ $-0.15 \mathrm{~V}$.

Figure 2 displays current-time recordings obtained at the composite electrode in $10.0 \mathrm{~mL}$ solutions of reversed micelles formed with ethyl acetate for successive $25-\mu \mathrm{L}$ additions of $0.04 \mathrm{~mol} \mathrm{~L}^{-1}$ stock microemulsions of phenol, 2,4-dimethylphenol, 4-chloro-3-methylphenol, and pentachlorophenol. As can be observed, the composite tyrosinase electrode exhibited a rapid response to the changes in

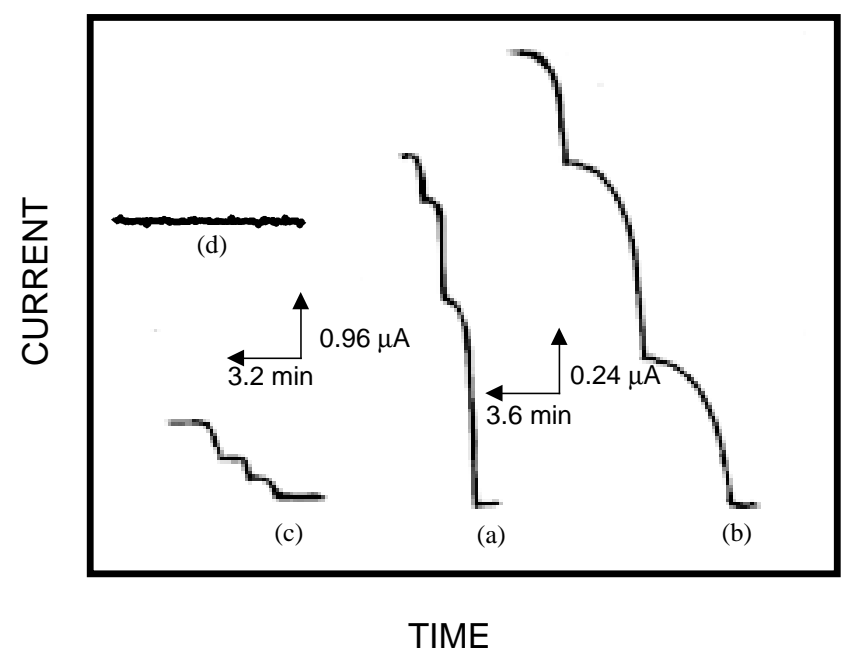

Figure 2. Current-time recordings at the graphite-70\%Teflontyrosinase electrode for successive $25-\mu \mathrm{L}$ additions of $0.04 \mathrm{~mol} \mathrm{~L}^{-1}$ stock microemulsions of: (a) phenol, (b) 4-chloro3-methylphenol, (c) 2,4-dimethylphenol, and (d) pentachlorophenol in reversed micelles formed with ethyl acetate. Other conditions as in Fig. 1. 
the substrate concentration for all the phenolic compounds tested, except for pentachlorophenol. This fast response is due both to the absence of a membrane barrier on the electrode surface, and to the absence of a covalent immobilization of the enzyme to graphite. No response was found after pentachlorophenol additions because this compound has all its ortho-positions substituted and hence the formation of the corresponding 1,2-quinone is not possible. Moreover, the steady-state currents obtained for phenol and 4-chloro-3methylphenol, with the two ortho-positions free, were much higher than that of the substrate with only one ortho-position free. Furthermore, when comparing the signals obtained for phenol and 4-chloro-3-methylphenol, it can be deduced that the time to reach the steady-state was considerably shorter for phenol, which may be due to the different solubility in water of these compounds. As the enzyme reaction takes place in the aqueous microdomains at the electrode surface [17], a partitioning equilibrium of the substrates between the aqueous and organic microdomains is established. Therefore, the compounds less soluble in water will need a longer time to attain this equilibrium, and hence the kinetics of the enzyme reaction will be slower.

Finally, it should be mentioned that no amperometric signals were observed after successive additions of the phenolic compounds when a composite graphite-Teflon electrode with no enzyme incorporated was employed.

\section{Nature of the emulsifying agent}

Assays on the performance of the graphite-Teflon-tyrosinase composite biosensor were made in reversed micelles formed with different surfactants: an anionic surfactant (AOT), a cationic surfactant (Hyamine 3500), and a non-ionic surfactant (Triton X-405, which also needed an electrolyte such as TBAP [5]). Although good steady-state amperometric responses were obtained for $0.4 \mathrm{mM}$ phenol in all cases, the reproducibility of these signals was not sufficiently good in the emulsions formed with the cationic and non-ionic surfactants, which can be due to the lower stability found for these reversed micelles, even with low percentages of aqueous phase, when compared with those formed with AOT. Consequently, AOT was selected as the emulsifying agent for further work.

Effect of the content of the aqueous dispersed phase, and of the surfactant concentration in the reversed micelles

Figure 3 shows the influence of the aqueous phosphate buffer solution percentage in the reversed micelle on the amperometric response for a constant concentration of phenol, 4-chloro-3-methylphenol, and 2,4-dimethylphenol. Only for aqueous phase contents higher than $2 \%$, measurable signals could be obtained for the three phenolic compounds, the signal increasing with the phosphate buffer percentage up to approximately a $5 \%$, indicating that for this content the enzyme hydration on the electrode surface is optimum for its enzymatic activity. Water contents higher than $6 \%$ gave

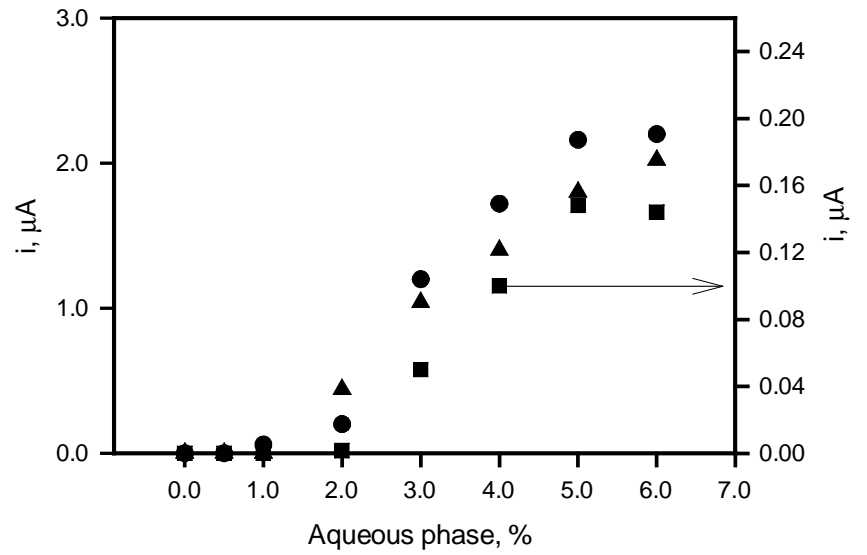

Figure 3. Effect of the dispersed aqueous phase percentage on the steady-state current in reversed micelles formed with ethyl acetate; $0.4 \mathrm{mM}$ phenol (A), 4-chloro-3-methylphenol $(\bullet)$, and 2,4-dimethylphenol ( $\square$ ). Other conditions as in Fig. 1.

rise to the breaking of the emulsion. A $5 \%$ of phosphate buffer solution was chosen to prepare the reversed micelles.

This aqueous phase content is higher than that optimized for tyrosinase amperometric biosensors prepared by direct adsorption of the enzyme on the electrode surface [4]. In these electrodes, where the enzyme is not very strongly attached to the surface, the maximum water percentage is limited by the solubilization of the enzyme in the aqueous microdroplets in the reversed micellles. However, no enzyme solubilization effect was found when using graphiteTeflon electrodes, where the enzyme is physically entrapped into the bulk of the rigid composite matrix, and, consequently, only aspects as the higher steady-state current obtained or the stability of the own emulsion need to be taken into account.

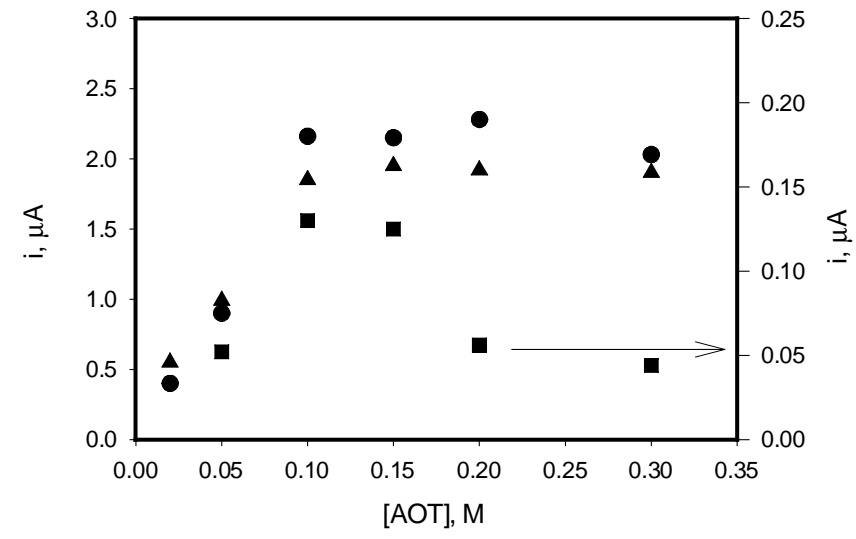

Figure 4. Influence of the AOT concentration on the steady-state current for $0.4 \mathrm{mM}$ phenol (A), 4-chloro-3-methylphenol $(\Theta)$, and 2,4-dimethylphenol $(\square)$ in reversed micelles formed with ethyl acetate. Other conditions as in Fig. 1. 


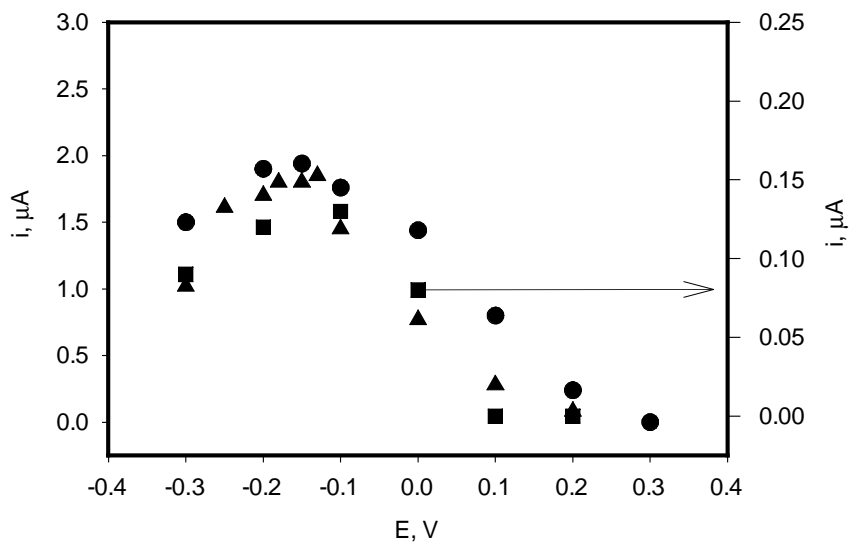

Figure 5. Influence of the applied potential on the steady-state current for $0.4 \mathrm{mM}(\Delta)$ phenol, ( $(\bullet)$ 4-chloro-3-methylphenol, and (口) 2,4-dimethylphenol in reversed micelles at a graphite$70 \%$ Teflon-tyrosinase composite electrode.

On the other hand, the influence of the AOT concentration on the amperometric response obtained for the above mentioned phenolic compounds is displayed in figure 4. As can be observed, maximum signals were obtained in all cases for an AOT concentration of around $0.1 \mathrm{~mol} \mathrm{~L}^{-1}$. From this value, the steady-state current remained practically constant for phenol and 4-chloro-3-methylphenol, but decreased in the case of 2,4-dimethylphenol. Therefore, a surfactant concentration of $0.1 \mathrm{~mol} \mathrm{~L}^{-1}$ was selected for further work.

\section{Effect of the applied potential}

The dependence of the composite tyrosinase electrode response on the applied potential was evaluated over the potential range from +0.30 to $-0.30 \mathrm{~V}$ for a $0.4 \mathrm{mM}$ concentration of phenol, 4-chloro-3-methylphenol and 2,4dimethylphenol (Fig. 5). As expected, a similar shape was observed for all the phenolic compounds with a rapid increase of the amperometric current between +0.20 and $-0.15 \mathrm{~V}$, followed by a decrease in the current at more negative potentials, which may be due to the polymerization of the corresponding o-quinone produced at these negative potentials [4]. The behaviour shown in Fig. 5 indicates that the 1,2-quinone formed in the enzymatic reaction for each of the tested substrates is reduced at very similar potentials. Consequently, a potential value of $-0.15 \mathrm{~V}$ was chosen for subsequent studies.

\section{Stability of the graphite-Teflon-tyrosinase composite electrode}

The useful lifetime of graphite-Teflon-tyrosinase composite electrodes in reversed micelles was studied by considering different aspects: (a) repeatability of the amperometric response with no electrode surface regeneration; (b) reproducibility of the amperometric signal after regenerating the electrode surface by polishing; (c) stability of one single composite electrode with time; (d) reproducibility in the fabrication of different electrodes; and (e) effect of the storage time of the pellet from which electrodes are constructed (see Experimental Section). All these studies were carried out in $10.0 \mathrm{~mL}$ of reversed micelles containing $0.4 \mathrm{mM}$ phenol as the substrate.

A set of amperometric measurements at $-0.15 \mathrm{~V}$ for 10 different reversed micelles with no regeneration of the electrode surface yielded a relative standard deviation (RSD) value for the steady-state current of $3.8 \%$.

One of the most advantageous properties of the use of composite enzyme electrodes is the possibility of obtaining a "new" electrode surface by simple polishing. Thus, the reproducibility of the amperometric response was tested after regeneration of the electrode surface by polishing for approximately $5 \mathrm{~s}$ on a 150 grit $\mathrm{SiC}$ paper. Three successive measurements were made after each polishing and a total of 10 polishings was performed. A RSD of $8.8 \%$ was obtained for the ten steady-state current mean values of each series, indicating that the composite bioelectrode yielded acceptably reproducible amperometric responses after being subjected to the regeneration procedure, and that the enzyme is uniformly distributed into the bulk of the electrode matrix.

On the other hand, the stability of one single composite enzyme electrode with time was checked by using two different approaches: (a) by performing everyday five measurements of different $0.4 \mathrm{mM}$ phenol emulsions with the electrode called "electrode A", and (b) by storing the electrode for some days after performing five measurements of different $0.4 \mathrm{mM}$ phenol emulsions for 3-4 consecutive days ("electrode B"), and then using it again. Figure 6 shows the control charts constructed for electrodes A and B. The mean value of the obtained steady-state current for the set of ten amperometric measurements with no electrode surface regeneration mentioned above, was used as the "target" value on the chart, whereas the upper and lower limits of control were set at $\pm 3 \mathrm{~s}$, where $\mathrm{s}$ is the standard deviation of this mean value. When a mean value of the five measurements carried out in the same day was out of the lower limit of control, the electrode surface was polished, and then the initial steady-state current could be restored. As it can be observed in figure 6 , the mean values of the amperometric signal remained inside the control limits over approximately 8-10 days for "electrode A", with no need of polishing the electrode surface. The RSD for all the steady-state current mean values obtained during 40 days (excluding the signals measured immediately before polishings) was of $7.3 \%$, which indicates that the composite tyrosinase electrode remained useful for at least this period of time. The control chart for "electrode B" also showed that when the amperometric signal decreased significantly, the initial response can be recovered by polishing of the electrode surface. Moreover, it can be deduced that a storage period of the electrode of 64 days (from the day 19 to the 84) did not affect this behaviour, which indicates that the loss of activity after this long storage time is only at the surface, and does not occur in the bulk of the electrode pellet. 

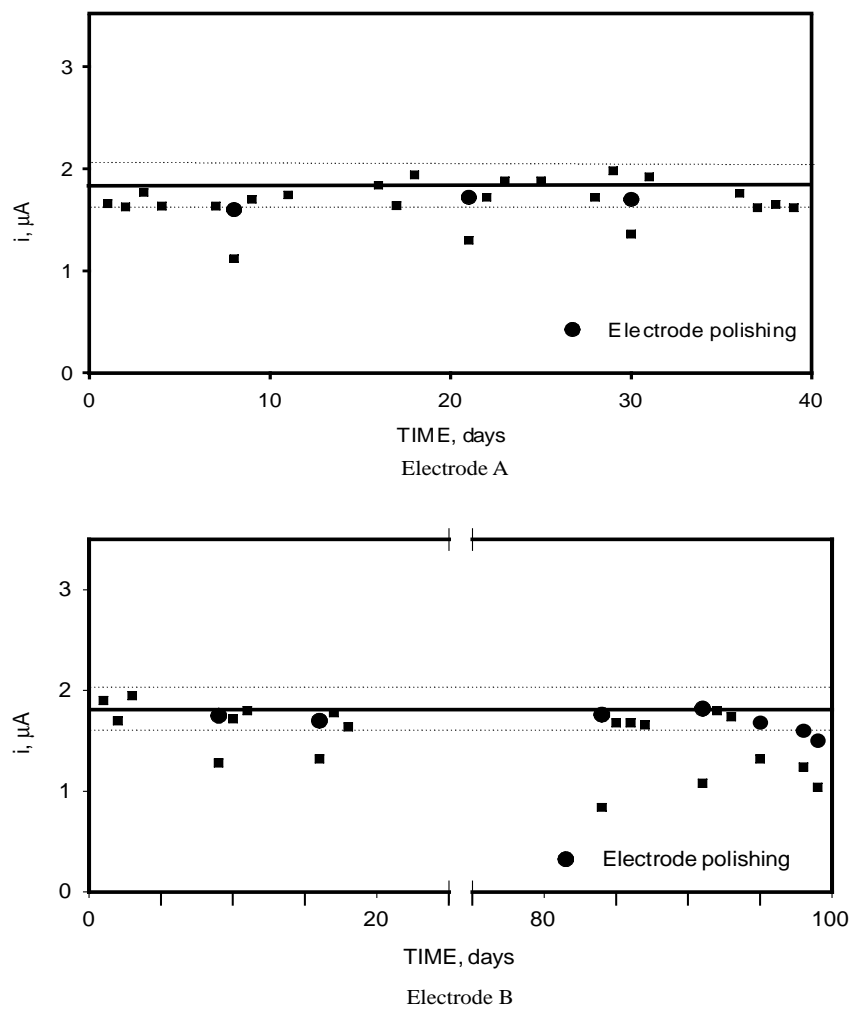

Figure 6. Control charts for the steady-state current dependence on time for $0.4 \mathrm{mM}$ phenol measured everyday (electrode A), and storing the electrode for some days after performing the measurements for 3-4 consecutive days (electrode B). Other conditions as in Fig. 1.

From approximately 95 days, the amperometric response could not be recovered by polishing. Taking into account that only five polishings were carried out over this period of time for this electrode ("electrode B"), see figure 6, and that, as it was demonstrated above, reproducible measurements were obtained after subjecting the same electrode to ten consecutive polishings, this loss of activity cannot be attributed to the fact that the thickness of the composite pellet becomes too thin after repetitive regeneration of the electrode surface. Since, as it will be discussed below, very long storage periods of the composite pellet at $4{ }^{\circ} \mathrm{C}$ did not either affect the enzyme activity, we have attributed the above mentioned loss of enzymatic activity to the changes of temperature undergone by the biosensor from the storage temperature $\left(4{ }^{\circ} \mathrm{C}\right)$ to the working temperature $\left(25 \pm 0.5^{\circ} \mathrm{C}\right)$ before each working session, and vice versa.

In any case, either because the enzyme activity is lost after a repetitive use and regeneration of the pellet surface, or because of the above mentioned changes of temperature during working days, the biocomposite pellets needed to be changed when the initial amperometric response could not be restored by polishing. Therefore, the reproducibility of
Table I. Reproducibility of different graphite-70\%teflontyrosinase electrodes fabricated from the same pellet and from different pellets. Five $0.4 \mathrm{mM}$ phenol steadystate current (i) measurements were carried out with each electrode in reversed micelles formed with ethyl acetate, $0.1 \mathrm{~mol} \mathrm{~L}^{-1} \mathrm{AOT}$, and a $5 \%$ of $0.05 \mathrm{~mol} \mathrm{~L}^{-1}$ phosphate buffer. Confidence intervals for a significance level of $0.05 ; \mathrm{E}_{\mathrm{ap}}=-0.15 \mathrm{~V}$.

\begin{tabular}{ccccc}
\hline PELLET & ELECTRODE & $i, \mu A$ & $\overline{\mathrm{i}}, \mathrm{mA}$ & $R S D, \%$ \\
\hline 1 & 1 & $1.86 \pm 0.08$ & & \\
& 2 & $1.84 \pm 0.08$ & & \\
& 3 & $1.82 \pm 0.09$ & $1.85 \pm 0.04$ & 2.0 \\
2 & 1 & $1.90 \pm 0.09$ & & \\
& 2 & $1.84 \pm 0.09$ & & \\
\hline
\end{tabular}

the analytical signals obtained from different electrodes fabricated from the same pellet and from different pellets is an essential aspect to be evaluated in order to asses the practical usefulness of the amperometric tyrosinase electrode in these predominantly non-aqueous media. Table I summarizes the results obtained for five electrodes, three of them fabricated from the same pellet, and the other two from a different pellet. Five amperometric measurements for phenol were carried out with each electrode. The RSD value for all the five electrodes was $2.0 \%$, which indicated that the fabrication procedure of the composite enzyme electrodes was reliable, and that reproducible electroanalytical responses can be achieved with different electrodes constructed in the same manner.

Finally, the effect of a long period of storage of the main composite pellet, when it was stored at $4{ }^{\circ} \mathrm{C}$ in a refrigerator, was also evaluated. After seven months of storage, no significant loss of the enzyme activity occurred, and similar (and reproducible) amperometric responses to those shown in table I were obtained when the bioelectrode was fabricated from such a stored pellet. Consequently, it can be stated that the enzyme immobilization method into the electrode matrix is suitable.

In conclusion, all the results obtained in these studies on the stability of the graphite-Teflon-tyrosinase composite electrode illustrate fairly well the robustness of the biosensor design developed.

\section{Kinetic parameters}

Other phenolic compounds, apart from those used above, were also employed as analytical substrates. Thus, catechol, 3,4-dimethylphenol, 3,5-dimethylphenol, 2,3-dimethylphenol, and 3-chloro-2-methylphenol were tested. The kinetics of the enzyme reaction for all these phenolic compounds fitted into a Michaelis-Menten type kinetic, as demonstrated by the calculation of the parameter $\mathrm{x}$ from the Hill's plots 
Table II. Kinetic parameters obtained with graphiteTeflon-tyrosinase composite electrodes for phenolic compounds in reversed micelles.

\begin{tabular}{lccc}
\hline SUBSTRATE & $x$ & $V_{m}(\mu \mathrm{A})$ & $K_{m, a p p}(\mathrm{mM})$ \\
\hline Catechol & 0.98 & 2.44 & 0.07 \\
Phenol & 0.95 & 2.03 & 0.16 \\
2,4-dimethylphenol & 1.03 & 2.98 & 6.6 \\
3,5-dimethylphenol & 0.96 & 2.36 & 18.8 \\
3,4-dimethylphenol & 1.02 & 2.66 & 0.08 \\
2,3-dimethylphenol & 0.96 & 2.64 & 101 \\
4-chloro-3-methylphenol & 0.98 & 4.17 & 0.41 \\
4-chloro-2-methylphenol & 0.98 & 4.35 & 269
\end{tabular}

$\left(\log \left[\left(\mathrm{i}_{\max } / \mathrm{i}\right)-1\right]\right.$ vs the $\log$ of the substrate concentration). This parameter was very close to 1 in all cases (see table II), indicating that the predominantly non-aqueous working medium did not disturb the Michaelis-Menten kinetic behaviour.

The calculation of the apparent Michaelis-Menten constants $\left(\mathrm{K}_{\mathrm{m}, \mathrm{app}}\right)$, and the maximum rate of the reaction $\left(\mathrm{V}_{\mathrm{m}}\right)$ was accomplished from the Lineweaver-Burk plots. The obtained values are summarized in table II. Taking into account the Michaelis-Menten theory [18], the dissociation constant of the enzyme-substrate complex (ES) is proportional to $\mathrm{K}_{\mathrm{m} \text {,app }}$, and $\mathrm{V}_{\max }$ is proportional to the catalytic constant $\left(\mathrm{k}_{\text {cat }}\right)$ for the conversion of the ES complex into the product plus the enzyme. The obtained results for all the phenolic compounds having at least one free ortho-position tested show that the stability of the ES complex depended on the structure of the substrate for a given homologous series. Furthermore, it can also be concluded that the substrates with one ortho-position occupied form less stable ES complexes, with the exception of 3,5-dimethylphenol which has a high Michaelis-Menten constant compared with the one obtained for the rest of the compounds from the homol- ogous series, in spite of having the two ortho-positions free. This may be due to a higher steric impediment to form the complex with this compound. Also, as expected, both phenol and catechol showed low Michaelis-Menten constants because their structure facilitates the enzyme-substrate complex formation.

Regarding the $\mathrm{V}_{\mathrm{m}}$ values, it can be deduced that the formation rate of the enzymatic reaction products depended on the nature of the homologous series, that is, this kinetic parameter was approximately the same for all the compounds belonging to the dimethylphenol family, as well as for phenol and catechol, whereas it was around twice for the chlorinated phenols.

\section{Calibration plots and analytical characteristics}

Table III summarizes the analytical characteristics of the linear portions of the corresponding calibration graphs obtained for each phenolic compound in the reversed micellar system. An applied potential of $-0.15 \mathrm{~V}$ was always applied. As can be deduced, the sensitivity was higher for those compounds having lower apparent Michaelis-Menten constants, as it is predicted theoretically. Furthermore, a wide range of linearity was found for chlorinated phenols which can be attributed to the faster kinetics for the formation of the enzymatic reaction products for these compounds commented above.

The values of the limits of determination and detection (Table IV) were calculated according to the 10s [19] and $3 \mathrm{~s}_{\mathrm{b}} / \mathrm{m}$ criteria [20], respectively, where $\mathrm{m}$ is the slope of the linear range of the corresponding calibration plot, and $s_{b}$ was the estimated as the standard deviation $(n=10)$ of the signals from different solutions of the substrates at the concentration levels shown in table IV. Moreover, RSD values for such concentration levels are also displayed in table IV. It can be said that the detection limits obtained with the graphite-Teflon-tyrosinase composite electrodes are, in general, considerably better than those found with tyrosinase amperometric biosensors prepared by direct adsorption of the enzyme on the electrode surface [4].

Table III. Analytical characteristics of the calibration plots for different phenolic compounds at graphite-Teflon-tyrosinase composite electrodes in reversed micelles.

\begin{tabular}{lcccc}
\hline Substrate & $\begin{array}{c}\text { Linear range } \\
\left(\mathrm{mol} \mathrm{L}^{-1}\right)\end{array}$ & $\begin{array}{c}\text { Slope } \\
\left(\mu \mathrm{A} \mathrm{mol} \mathrm{H}^{-1} \mathrm{~L}\right)\end{array}$ & $\begin{array}{c}\text { Intercept } \\
(\mu \mathrm{A})\end{array}$ & $r$ \\
Catechol & $(1-30) \times 10^{-6}$ & $(3.6 \pm 0.4) \times 10^{4}$ & $(2 \pm 5) \times 10^{-2}$ & 0.997 \\
Phenol & $(4-80) \times 10^{-6}$ & $(1.28 \pm 0.05) \times 10^{4}$ & $(0.04 \pm 2) \times 10^{-2}$ & 0.998 \\
2,4-dimethylphenol & $(0.05-3.0) \times 10^{-3}$ & $(2.8 \pm 0.2) \times 10^{2}$ & $(-2 \pm 2) \times 10^{-2}$ & 0.997 \\
3,5-dimethylphenol & $(2-20) \times 10^{-3}$ & $62 \pm 2$ & $(-3 \pm 3) \times 10^{-2}$ & 0.999 \\
3,4-dimethylphenol & $(1-40) \times 10^{-6}$ & $(2.1 \pm 0.1) \times 10^{4}$ & $0.01 \pm 0.02$ & 0.997 \\
2,3-dimethylphenol & $(2-30) \times 10^{-3}$ & $31 \pm 1$ & $(-4 \pm 2) \times 10^{-2}$ & 0.998 \\
4-chloro-3-methylphenol & $(4-500) \times 10^{-6}$ & $(5.12 \pm 0.02) \times 10^{4}$ & $(3 \pm 4) \times 10^{-2}$ & 0.998 \\
4-chloro-2-methylphenol & $(5-80) \times 10^{-3}$ & $14.9 \pm 0.7$ & $(-7 \pm 3) \times 10^{-2}$ & 0.998 \\
\hline
\end{tabular}


Table IV. Analytical characteristics for the determination of several phenolic compounds at graphite-Teflon-tyrosinase composite electrodes in reversed micelles.

\begin{tabular}{lcccc}
\hline Substrate & $\begin{array}{c}\text { Concentration } \\
(\mathrm{mol} \mathrm{L})\end{array}$ & $\begin{array}{c}R S D \\
(\%)\end{array}$ & $\begin{array}{c}\text { Detection limit } \\
\left.(\mathrm{mol} \mathrm{L})^{-1}\right)\end{array}$ & $\begin{array}{c}\text { Determination } \\
\text { limit }\left(\mathrm{mol} \mathrm{L}^{-1}\right)\end{array}$ \\
Catechol & $4 \times 10^{-6}$ & 8.7 & $4.65 \times 10^{-7}$ & $1.55 \times 10^{-6}$ \\
Phenol & $1 \times 10^{-5}$ & 6.8 & $1.1 \times 10^{-6}$ & $3.7 \times 10^{-6}$ \\
2,4-dimethylphenol & $5 \times 10^{-5}$ & 8.2 & $3.38 \times 10^{-5}$ & $1.13 \times 10^{-4}$ \\
3,5-dimethylphenol & $2 \times 10^{-3}$ & 6.4 & $2.0 \times 10^{-4}$ & $6.66 \times 10^{-4}$ \\
3,4-dimethylphenol & $3 \times 10^{-6}$ & 8.6 & $1.0 \times 10^{-6}$ & $3.3 \times 10^{-6}$ \\
2,3-dimethylphenol & $2 \times 10^{-3}$ & 7.5 & $4.74 \times 10^{-4}$ & $1.58 \times 10^{-3}$ \\
4-chloro-3-methylphenol & $1 \times 10^{-5}$ & 7.7 & $4.4 \times 10^{-7}$ & $1.5 \times 10^{-6}$ \\
4-chloro-2-methylphenol & $5 \times 10^{-3}$ & 6.6 & $1.3 \times 10^{-3}$ & $4.4 \times 10^{-3}$ \\
\hline
\end{tabular}

\section{Conclusions}

All the above results demonstrate fairly well that the graphite-Teflon-tyrosinase composite electrodes constitute robust amperometric biosensors able to work in predominantly non-aqueous media, such as reversed micelles, and suitable for monitoring ortho-diphenols and phenols having at least one free ortho-position. Besides this compatibility with predominantly non-aqueous media, this biosensor design shows important practical advantages such as an easy fabrication by physical inclusion of the enzyme into the bulk of the electrode matrix with no need of covalent bindings, a good renewability of the surface by polishing, and a longterm operation and stability.

\section{Acknowledgements}

Financial support from the Subdirección General de Formación y Promoción del Conocimiento (Project PB960640), and Comunidad de Madrid (Project 07M/0470/1997) is gratefully acknowledged.

\section{References}

1. Del Cerro, M.A.; Cayuela, G.; Reviejo, A.J.; Pingarrón, J.M. Electroanalysis 1997, 9, 113.

2. Cayuela, G.; Peña, N.; Reviejo, A.J.; Pingarrón, J.M. The Analyst 1998, 123, 371
3. Ortiz, G.; González, M.C.; Reviejo, A.J.; Pingarrón, J.M. Anal. Chem. 1997, 69, 3521.

4. Liu, F.; Reviejo, A.J.; Pingarrón, J.M.; Wang, J. Talanta 1994, $41,455$.

5. Reviejo, A.J.; Liu, F.; Pingarrón, J.M.; Wang, J. J. Electroanal. Chem. 1994, 374, 133.

6. Reviejo, A.J.; Fernández, C.; Liu, F.; Pingarrón, J.M.; Wang, J. Anal. Chim. Acta 1995, 315, 93.

7. ISO 6439. "Water Quality. Determination of Phenol Index" 1990.

8. ISO 8165-1. "Water Quality. Determination of Selected Phenols" 1992.

9. Lutz, E.; Domínguez, E. Electroanalysis 1996, 8, 117.

10. Li, J.; Chia, L.S.; Goh, N.K.; Tan, S.N. Anal. Chim. Acta 1998, 362, 203.

11. Adeyoju, O.; Iwuoka, E.J.; Smyth, M.R.; Leech, D. Analyst 1996, 121, 1885.

12. Deng, Q.; Dong, S. J. Electroanal. Chem. 1997, 435, 11.

13. Iwuota, E.J.; Smyth, M.R. Biosensors and Bioelectronics 1997, 12,53 .

14. Walsh, C. In: Enzymatic Reaction Mechanisms (Freeman Ed.) New York, 1979, 461.

15. Wang, J.; Lu, F.; López, A. Biosensors and Bioelectronics 1994, 9 .

16. Laane, C.; Boeren, S.; Vos, K.; Veeger, C. Biotech. Bioenerg. 1987, 30, 81.

17. Larsson, K. Enzyme Catalysis in Microemulsions. Doctoral Thesis, University of Lund, Sweeden, 1980.

18. Cornish-Bowder, A; Wharton, C.W. In: Enzyme Kinetics (Rickwood D, and Male D, eds), IRL Press, Oxford, 1988, 118.

19. ACS Committee on Environmental Improvement. Principles of Environmental Analysis Anal. Chem. 1983, 55, 2210.

20. Hasebe, K.; Osteryoung, J. Anal. Chem. 1975, 47, 2412. 